\title{
EDITORIAL
}

\section{Lung volume: a principle determinant of airway smooth muscle function}

\author{
C.G. Irvin
}

\begin{abstract}
Asthma is a syndrome that is characterised by clinical features that centre on disorders of lung function; indeed, the diagnosis of asthma is best made by obtaining lung function tests [1-3]. Asthma, unlike other lung diseases, shows a functional and temporal instability, where lung function can be both cyclic (e.g. nocturnal asthma) and prone to sudden falls (e.g. exposure to allergens) in the ability to move air, as assessed by peak flow variability. Yet the mechanisms that may link peak flow variability and airways hyperresponsiveness are largely unknown $[4,5]$. One possibility is that both of these common features of asthma are linked by lung volume or a lung volume-dependent mechanism.
\end{abstract}

\section{Lung volume, airways smooth muscle and airway hyperresponsiveness}

Lung volume is a pivotal determinant of airway smooth muscle (ASM) function and lung function. Animal studies most clearly demonstrate the importance of how acute alterations in lung volume significantly alter the response of lung mechanics to bronchoactive agents. For example, NAGASE et al. [6], who elevated lung volume using positive end-expiratory pressure (PEEP), showed a $12 \%$ reduction in the response of airway resistance (Raw) to inhaled histamine for every $\mathrm{cm} \mathrm{H}_{2} \mathrm{O}$ of PEEP increase. BATES et al. [7], using a rat system where small volume oscillations were used to nearly instantaneously measure airway responses to injected methacholine, showed that an increase in lung volume $\left(2-6 \mathrm{cmH}_{2} \mathrm{O}\right.$ of PEEP) caused a reduction in the rate of rise in $R$ aw by an order of magnitude. Collectively, these findings suggest that ASM contractility is profoundly influenced by lung volume, effects that are much larger than often observed in response to inflammatory mediators. The situation is no less important in humans. This is strikingly seen in the study of DING et al. [8], where it was shown that $500 \mathrm{~mL}$ changes in lung volume could, in essence, cause airway hyperresponsiveness (AHR) in controls and largely reverse AHR in asthmatics, a truly remarkable finding. SKLOOT et al. [9], in their seminal paper, demonstrated that when large breaths are prohibited, normal subjects became hyperresponsive to inhaled methacholine. These findings suggest that failure to periodically inflate the lung to high volumes allows for some protective mechanism to be lost $[9,10]$. This bronchoprotective effect, in more recent studies, has been shown to be much more potent than bronchodilation caused by a deep breath in controls [11]. In asthmatics (and even in patients with rhinitis), the bronchoprotective effect of a deep breath is lost regardless of the degree of asthma [12, 13]. Collectively, these studies suggest

Correspondence: C.G. Irvin, Vermont Lung Center, Dept of Medicine, College of Medicine, University of Vermont, 149 Beaumont Avenue HSRF 226, Burlington, VT 05405, USA. Fax: 1 8026568926. E-mail: charles.irvin@uvm.edu that periodic lung volume changes are a critical determinant of recovery from bronchospasm and in normal subjects serve to prevent AHR.

\section{Mechanisms}

How would a lack of periodic large volume breaths, like periodic sighs that everyone takes, alter ASM function? One mechanism has been suggested by FREDBERG and co-workers $[14,15]$. They propose that the failure to periodically stretch the activated ASM results in the ASM being altered, from a state of disequilibrium to a "latch" state where it is frozen. Given that under normal conditions the ASM is subjected to cyclic stretch, it may come as no surprise that ASM would have to adapt functionally to these cyclic changes in length. Failure to periodically inflate and stretch the ASM results in a potentially hyperresponsive state for the muscle or at least sets it up to respond abnormally to an asthma trigger.

Another important mechanism by which lung volume affects pulmonary function is through the mechanism of interdependence [16]. On the external wall of intrapulmonary airways there are radially arranged alveolar wall attachments. As volume increases, the pull or tethering of these alveolar wall attachments exerts an external force, dilating the airway lumen. This is a powerful effect. As lung volume changes from functional residual capacity (FRC) to residual volume, the pulmonary resistance falls by one-half or more [12-19]. Acute asthma (nocturnal asthma) or sleep onset results in rapid loss of this important defence mechanism [19]. Interdependence would be expected to affect bronchial more than extrathoracic airways, such as the trachea.

\section{Effects of chronic volume loss}

In the current issue of the European Respiratory Journal, MCCLEAN et al. [20] show for the first time how chronic loss of volume affects ASM function. In this clever model system, lung volume was chronically reduced by having sheep wear a leather corset for 4 weeks. Three groups were studied: neonates, adolescents and adults. While the FRC was reduced by $\sim 25 \%$, no significant changes in tidal volume or number of sighs were observed, nor were there changes in blood gases. Tracheal ASM contractility was unchanged, but in adolescents and adults bronchial ASM contractility was increased. There were no apparent differences in the amount of ASM, suggesting hypertrophy had not occurred. Moreover, neither myosin light chain (MLC) kinase content nor MLC phosphorylation of the bronchial smooth muscle were changed. Accordingly, it is unclear from this study what is the cause of increased bronchial contractibility. In addition, it is equally unclear how these findings may translate into altered in vivo function. The authors speculate that lack of deep breaths 
or chronic low lung volume cause ASM to reorganise, which is consistent with what is known about ASM plasticity [21-24].

\section{Implications}

The results of this study have many important implications. The first is that the marked change in ASM contractility or plasticity appears to occur after fairly mild alterations in length, which is consistent with the notion that the influence of lung volume is large. The fact that ASM contractility is not altered in neonates but that it is in adults was not commented upon by the authors. It may be speculated that neonates would suffer severely if changes in ASM contractility occurred during rapid lung growth, which may be inhibited by the leather corset restriction, and reinforces the point that the factors that affect lung function in infants are clearly not the same as in adults [25].

\section{Lung volume derecruitment and airways smooth muscle heterogeneity}

At first glance the results reported in this issue of the $E R J$ by MCCLEAN et al. [20] would seem to have little to do with asthma, but indeed the increase in ASM contractility observed with chronic volume loss may have important mechanistic implications. Asthma, even in the mildest forms, is associated with periodic airway closure and lung volume derecruitment that worsens with asthma severity [26,27]. An airways located behind closed airways may be subjected to the same forces and stimuli that occurred in the bronchioles removed from the corseted sheep. In the asthmatic lung, as the airways close and volume of the region falls due to gas reabsorption [28], a similar situation may occur. In such an airway, trapped beyond a point of larger airway closure, deep breaths may not result in bronchoprotection [11-13], thus, this mechanism could account for the well-known airway-to-airway heterogeneity of ASM function [29]. Alternatively, the bronchial airways are subjected, or not subjected with chronic volume, to tethering forces that would then determine the functional phenotype. Such a mechanism would be profoundly influenced by the known heterogeneous pressure changes that occur in the thorax when the rib cage motion is suppressed [30], which would be expected to contribute to the regional heterogeneity of the response.

\section{Clinical implications}

MCCLEAN et al. [20] suggest that the AHR of obesity may be the result of similar chronic volume loss [31, 32]. A more likely mechanism in the obese, as shown by JOHNSTON et al. [33], involves leptin, a pro-inflammatory cytokine-like protein, known to be elevated in the obese. This mechanism would not involve changes in lung volume. Other possibilities include other factors associated with obesity, such as diet [31, 32] or lack of exercise [34]. A more likely linkage between AHR and chronic volume loss is observed in patients with neural muscular disorders or chest wall abnormalities [35]. Here, limitation of the chest wall expansion, not unlike the effects of the leather corset observed by MCCLEAN et al. [20], is associated with increased airway responsiveness.

\section{Airways smooth muscle plasticity and phenotype}

The conclusion that ASM shows chronic changes in vivo consistent with plasticity, which is observed in more acute in vitro studies, is potentially very important. These experiments teach us that ASM is a much more dynamic cell type than previously thought. Aside from the well-known contractile phenotype, ASM has been shown to exhibit a secretory phenotype [36] and other functional forms seem possible. As an example, it has been shown that ASM secretes a wide array of potentially important mediators including interleukin (IL)-6, IL-8 and granulocyte macrophage colony-stimulating factor [37]. However, for the first time MCCLEAN et al. [20] have demonstrated remodelling of the bronchial ASM to a hyperresponsive phenotype due to chronic length inhibition, which suggests that lung volume per se is an important determinant of ASM function and phenotype.

\section{Unanswered questions}

This study raises many questions that need to be addressed. How fast do the changes occur? Hours, days, weeks? More importantly, how long do the changes persist after lung volume is returned to normal? Why are neonates unresponsive to chronic volume loss? What is the source of the change? Perhaps, the most significant question is what is the primary signal that initiates the response [38]? Is it volume or pressure?

Lung volume is an underappreciated factor that has a profound effect on nearly all aspects of the functioning of the lung. Yet, there is still poor understanding of all the functions and mechanisms of the lung controlled or influenced by lung volume. It appears that lung volume, either as a static signal as shown by the current study, or as a dynamic signal reflected by tidal volume or by sighs and deep breaths, to a large extent, determines the function phenotype of the airway smooth muscle. This suggests that volume or pressure has significant effects on genetic mechanisms and cell signalling in the airway smooth muscle and much of the lung in general [38]. Therefore, lung volume must have effects that go beyond those normally assessed in the pulmonary function laboratory, and these effects clearly extend into the nucleus itself [38]. Given the profound influence of lung volume on airway smooth muscle function, exploration of these volume-dependent molecular mechanisms should prove to be a fruitful avenue of future research.

\section{References}

1. National Asthma Education and Prevention Program Expert Panel. Report: Guidelines for the diagnosis and management of asthma. Update on selected topics. J Allergy Clin Immunol 2002; 110: S141-S219.

2. Kaminsky DA, Irvin CG. Lung Function in asthma. In: Barnes PJ, Grunstein MM, Leff A, Woolcock AJ, eds. Asthma. New York, Lippincott-Raven Publishers, 1997; 89: pp. $1277-1300$.

3. Eidelman DH, Irvin CG. Airway mechanics in asthma. In: Busse WW, Holgate ST, eds. Asthma and Rhinitis. 2nd Edn. Oxford, Blackwell Science, 2000; pp. 1237-1247.

4. Wagers SS, Irvin CG. The pharmacology of aerosolized airway challenge. Respir Care Clin N Am 1999; 5: 633-648.

5. Parameswaran K, Belda J, Sears MR. Use of peak flow variability and methacholine in responsiveness in predicting changes from pre-test diagnosis of asthma. Eur Respir $J$ 1999; 14: 1358-1362.

6. Nagase T, Martin JG, Ludwig MS. Comparative study of mechanical interdependence: effect of lung volume on Raw during induced constriction. J Appl Physiol 1993; 75: 25002505.

7. Bates JHT, Schuessler TF, Dolman C, Eidelman DH. Temporal dynamics of acute isovolume bronchoconstriction in the rat. J Appl Physiol 1997; 82: 55-62. 
8. Ding D, Martin J, Macklem PT. Effects of lung volume on maximal methacholine-induced bronchoconstriction in normal humans. J Appl Physiol 1987; 62: 1324-1330.

9. Skloot G, Permutt S, Togias A. Airway hyperresponsiveness in asthma: a problem of limited smooth muscle relaxation with inspiration. J Clin Invest 1995; 96: 2293-2403.

10. Brusasco V, Crimi E, Barisione G, Spanevello A, Rodarte J, Pellegrino R. Airway responsiveness to methacholine: effect of deep inhalations and inflammation. J Appl Physiol 1999; 87: $567-573$.

11. Scichilone N, Kapsali T, Permutt S, Togias A. Deep inhalation-induced bronchoprotection is stronger than bronchodilation. Am J Respir Crit Care Med 2000; 162: 910-916.

12. Kapsali T, Permutt S, Lauke B, Scichilone N, Togias A. Potent bronchoprotective effect of deep inspiration and its absence in asthma. J Appl Physiol 2000; 89: 711-720.

13. Scichilone N, Permutt S, Togias A. The lack of the bronchoprotective and not the bronchodilatory ability of deep inspiration is associated with airways hyperresponsiveness. Am J Respir Crit Care Med 2001; 163: 413-419.

14. Fredburg JJ, Inouye $\mathrm{D}$, Miller $\mathrm{B}$, et al. Airway smooth muscle, tidal stretches and dynamically determined contractile states. Am J Respir Crit Care Med 1997; 156: 1752-1759.

15. Fredburg JJ. Airway smooth muscle in asthma: flirting with disaster. Eur Respir J 1998; 12: 1252-1256.

16. Mead J, Takishima T, Leith D. Stress distribution in lung: a model of pulmonary elasticity. J Appl Physiol 1970; 28: 596608.

17. Butler J, Caro CG, Alcala R, Dubois AB. Physiological factors affecting airway resistance in normal subjects and in patients with obstructive respiratory disease. J Clin Invest 1960; 39: 584-591.

18. Vincent NJ, Knudson R, Leith DE, Macklem PT, Mead J. Factors influencing pulmonary resistance. J Appl Physiol 1970; 29: 236-243.

19. Irvin CG, Pak J, Martin RJ. Airway-parenchyma uncoupling in nocturnal asthma. Am J Respir Crit Care Med 2000; 161: 50-56.

20. McClean MA, Matheson MJ, McKay K, et al. Low lung volume alters contractile properties of airway smooth muscle in sheep. Eur Respir $J$ 2003; 22: 50-56.

21. Gunst SJ. Contractile force of canine airway smooth muscle during cyclic length changes. J Appl Physiol 1983; 55: 759769.

22. Gunst SJ, Meiss RA, Wu MF, Rowe M. Mechanism for the mechanical plasticity of tracheal smooth muscle. $\mathrm{Am}$ J Physiol 1995; 265: C1267-C1276.

23. Seow CY, Pratusevich VR, Ford LE. Series-to-parallel transition in the filament lattice of airway smooth muscle. J Appl Physiol 2000; 89: 869-876.

24. Gunst SJ, Wu MF. Plasticity of airway smooth muscle stiffness and extensibility: role of length-adaptive mechanisms. J Appl Physiol 2001; 90: 741-749.

25. Irvin CG. Interaction between the growing lung and asthma: role of early intervention. J Allergy Clin Immunol 2000; 105: S540-S546.

26. Kaminsky DA, Bates JHT, Irvin CG. Effects of cool, dry air stimulation on peripheral lung mechanics in asthma. $\mathrm{Am}$ J Respir Crit Care Med 2000; 162: 179-186.

27. Kraft M, Pak J, Martin RJ, Kaminsky DA, Irvin CG. Distal lung dysfunction at night in nocturnal asthma. Am J Respir Crit Care Med 2001; 163: 1551-1556.

28. Gunst S, Stropp J, Service J. Mechanical modulation of pressure-volume characteristics of contracted canine airways in vitro. J Appl Physiol 1990; 68: 2223-2229.

29. Brown RH, Georgakopoulas J, Mitzner W. Individual canine airway responsiveness to aerosol histamine and methacholine in vivo. Am J Respir Crit Care Med 1998; 157: 491-497.

30. Irvin CG, Sampson M, Engel L, Grassino A. Effect of breathing pattern on esophageal pressure gradients in humans. J Appl Physiol 1984; 57: 168-175.

31. Shaheen SO. Obesity and asthma: cause for concern? Clin Exp Allergy 1999; 29: 291-293.

32. Litonjua AA, Sparrow D, Celeton JC, DeMolles D, Weiss ST. Association of body mass index with the development of methacholine airways hyperresponsiveness in men: the normative aging study. Thorax 2002; 57: 581-585.

33. Johnston RA, Schwartzman IN, Krishma GG, Shore SA. Effect of leptin on ozone $\left(\mathrm{O}_{3}\right)$-induced airway hyperactivity and injury in C57BL16 mice. Am J Respir Crit Care Med 2002; 165: A1776.

34. Arborelius M Jr, Svenonius E. Decrease of exercise-induced asthma by physical training. Eur J Respir Dis Suppl 1984; 136: 25-31.

35. Grimm DR, Lesser AE, Bauman WA, Almenoff PL. Airway hyperresponsiveness to ultrasonically nebulized water in subjects with tetrasplegia. J Appl Physiol 1999; 86: 1165-1169.

36. Halayko AJ, Solway J. Molecular mechanisms of phenotype plasticity in smooth muscle cells. J Appl Physiol 2001; 90: 358-368.

37. Amrami Y, Panetlieri RA. Airways smooth muscle: contraction and beyond. Int J Biochem Cell Biol 2003; 35: 272-276.

38. Waters CM, Sporn PHS, Liu M, Fredberg JJ. Cellular biomechanics in the lung. Am J Physiol Lung Cell Mol Physiol 2002; 283: L503-L509. 